\title{
Species diversity of bats along an altitudinal gradient on Mount Mulanje, southern Malawi
}

\section{Journal Article}

Author(s):

Curran, Michael; Kopp, Mirjam; Beck, Jan; Fahr, Jakob

Publication date:

2012-05

Permanent link:

https://doi.org/10.3929/ethz-b-000048464

Rights / license:

In Copyright - Non-Commercial Use Permitted

Originally published in:

Journal of Tropical Ecology 28(3), https://doi.org/10.1017/S0266467412000193 


\title{
Species diversity of bats along an altitudinal gradient on Mount Mulanje, southern Malawi
}

\author{
Michael Curran*, ${ }^{*}, 1$, Mirjam Kopp*, Jan Beck* and Jakob Fahrł §§
}

\author{
* University of Basel, Department of Environmental Sciences, Biogeography, St. Johanns-Vorstadt 10, 4056 Basel, Switzerland \\ $\dagger$ Swiss Federal Institute of Technology (ETH) Zurich, Institute of Environmental Engineering, Wolfgang-Pauli-Str. 15, 8093 Zürich, Switzerland \\ $\ddagger$ University of Ulm, Institute of Experimental Ecology, Albert-Einstein Allee 11, 89069 Ulm, Germany \\ $\S$ University of Braunschweig, Zoological Institute, Division of Evolutionary Biology, Mendelssohnstr. 4, D-38106 Braunschweig, Germany \\ (Accepted 24 February 2012)
}

\begin{abstract}
A climate model, based on effects of water availability and temperature, was recently proposed to explain global variation in bat species richness along altitudinal gradients. Yet such studies are sparse in the tropics and nearabsent in Africa. Here we present results from an altitudinal study of bat diversity from Mount Mulanje, Malawi. Using ground nets, canopy nets and harp traps, we sampled eight sites across three habitat zones from $630 \mathrm{~m}$ to $2010 \mathrm{~m}$ asl. We assessed the influence of climatic, geographic and biotic variables on measures of estimated species richness, Fisher's $\alpha$, and an unbiased index of compositional turnover. We recorded 723 individuals and 30 species along the gradient, revealing a 'low plateau' pattern in estimated species richness, peaking at $1220 \mathrm{~m}$, which is congruent with the global climate model. Measures of local habitat structure significantly explained a large degree of variation in species richness and compositional turnover between sites. Fisher's $\alpha$ was further significantly correlated to mean annual relative humidity, suggesting a background climatic influence.
\end{abstract}

Key Words: Africa, altitude, biodiversity, bats, Chiroptera, elevation, environmental gradients, habitat structure, species richness

\section{INTRODUCTION}

Altitudinal gradients provide an attractive setting for biodiversity research because they offer the potential to test hypotheses of global processes at local scales (Rahbek 2005). The altitude-richness relationship is influenced by a number of factors including taxonomy (Goodman \& Rasolonandrasana 2001, Graham 1990), scale (Colwell \& Lees 2000, McCain 2007a, Romdal \& Grytnes 2007) and evolutionary history (Smith et al. 2007), and varies both spatially and temporally through seasonal and climatic change (Grytnes \& McCain 2007, Sánchez-Cordero 2001). There is a general recognition of three predominant patterns: declining species richness with altitude (declining); a low plateau where richness remains high until the mid-altitudes before declining (low plateau); and a mid-altitude peak in species richness (midpeak) (Grytnes \& McCain 2007).

A global meta-analysis for bats (Chiroptera) demonstrated the presence of all three such patterns, apparently

\footnotetext{
${ }^{1}$ Corresponding author. Email: curran@ifu.baug.ethz.ch
}

dependent on an interplay between temperature and water availability as determined by the surrounding regional climate (approximated by latitude) of the mountain in question (McCain 2007b). On mountains with arid lowlands, the peak in species richness is predicted to occur at mid-altitudes, where a unimodal water-availability gradient reaches a maximum while temperatures are still relatively high. Where water is not a limiting factor, as in the humid tropics, richness peaks at low altitudes where temperatures are highest. Such largescale meta-studies are extremely useful for characterizing broad-scale patterns and untangling the causal factors that create them. Yet adequate geographic representation is an important factor, hence it is worth noting that the meta-analysis of McCain (2007b) lacked data from the African continent. In terms of biodiversity patterns and overall levels of species richness of bats and many other groups, Africa appears to stand as the 'odd man out' because of its unique geological and climatic history (Findley \& Wilson 1983, Meggers et al. 1973; but see Fahr \& Kalko 2011). This presents an interesting opportunity to test a model that was largely developed using data from Asia and the Americas on a different continent. 


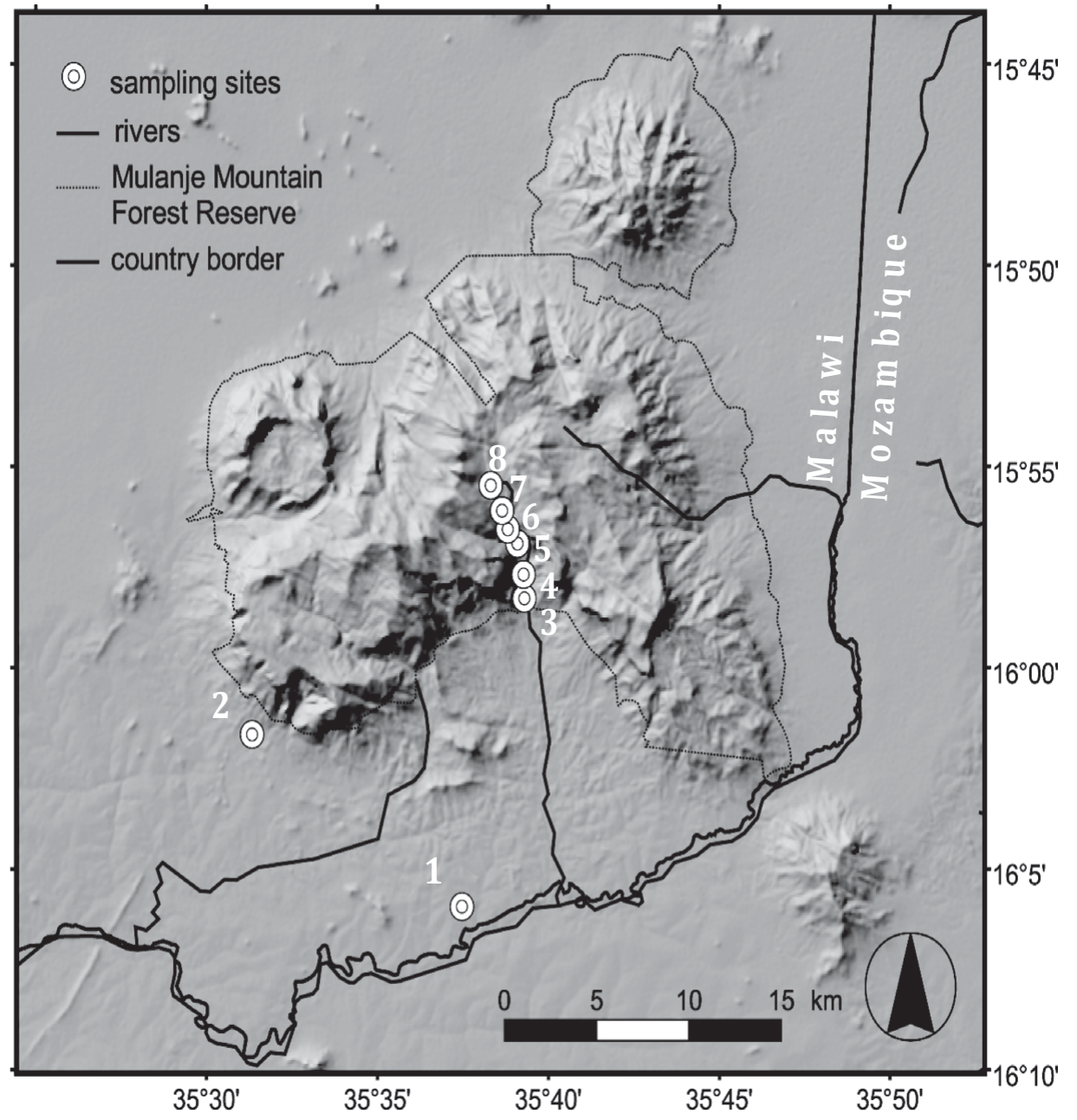

Figure 1. Shaded relief map of the study area with locations of sampling sites.

To our knowledge, bat diversity along an altitudinal gradient has not yet been studied systematically in Africa. In this paper, we present novel data from Mount Mulanje, southern Malawi, a region surveyed poorly for bats in the past (Happold \& Happold 1997, Happold et al. 1987). We use these data to test the predictions generated by the climatic model of McCain (2007b), which estimates a peak in species richness at $c .1000 \mathrm{~m}$ on Mt. Mulanje according to its latitudinal position.

\section{STUDY AREA}

Mount Mulanje represents Malawi's only UNESCO Biosphere Reserve. It rises from a relatively featureless plain to $3002 \mathrm{~m}$ asl, covering an area of roughly $650 \mathrm{~km}^{2}$ at $15^{\circ} 50^{\prime}-16^{\circ} 03^{\prime} \mathrm{S}, 35^{\circ} 30^{\prime}-35^{\circ} 47^{\prime} \mathrm{E}$ (Figure 1). The mountain contains a remarkable variety of habitats that support many rare, threatened and endemic species, which include the endemic Mulanje cedar, Widdringtonia whytei Rendle, a critically endangered flagship species (Bayliss et al. 2007). The montane forests are part of a National Forest Reserve, but in response to growing rates of deforestation and illegal encroachment, reserve boundaries have been constricted five times since their delineation in 1927 (Bouvier 2006; available at http://www.joyhecht.net/mulanje/refs/BouvierIoana.Mulanje.LC.TimeSeries.2006.pdf). This period has witnessed a near-total loss of lowland forests (replaced by agricultural land, including tea, Acacia and Eucalyptus plantations) and large reductions in the extent of midaltitude forest (between 1972 and 2002, submontane and montane forest has declined at a rate of $0.5 \% \mathrm{y}^{-1}$; Bouvier 2006).

\section{Climate}

Rainfall regimes on Mount Mulanje typically show a peak from November to April where many seasonal streams and rivers become active and flash floods are common after heavy storms. Average annual precipitation (rainfall 
records 1969-1978) is $1725 \mathrm{~mm}$ in the lowland, rising to $2425 \mathrm{~mm}$ at the entrance to the Ruo Gorge where mid-altitude vegetation starts $(900 \mathrm{~m})$, and increasing further to $3108 \mathrm{~mm}$ on the Lichenya Plateau west of our gradient (1850 m; Dowsett-Lemaire 1988). A large proportion of this precipitation (17-21\%) arrives during the dry season (May-September) in the form of mist, drizzle and occasional showers brought by moist maritime air from the Mozambique Channel to the high plateaux and steep slopes. Mean annual temperatures are $22.6{ }^{\circ} \mathrm{C}$ at the lowland site $(630 \mathrm{~m}), 15-19{ }^{\circ} \mathrm{C}$ at altitudes of $1400-1800 \mathrm{~m}$ and dropping to $13-15^{\circ} \mathrm{C}$ on the high plateaux above $2000 \mathrm{~m}$ (Dowsett-Lemaire 1988).

\section{Sampling sites}

We studied bat diversity along a transect consisting of eight sampling sites spanning $1380 \mathrm{~m}$ altitude. This covered roughly $55 \%$ of the altitudinal gradient on Mount Mulanje, which extends from lowland plains undulating at $500-600 \mathrm{~m}$ to the peak of the mountain at $3002 \mathrm{~m}$. Only $5 \%$ of the gradient were unrepresented at lower altitudes while about $40 \%$ were unrepresented at the top of the gradient. Six sampling sites were located within evergreen mid-altitude and high-altitude forest in the Ruo Gorge (sites 3-8) as well as two spatially detached sites in the last areas of lowland forest at the mountain base (site 1, located $14.6 \mathrm{~km} \mathrm{SSW}$ of the gorge entrance, and site 2, located $10 \mathrm{~km} \mathrm{~W}$ of the gorge entrance; Figure 1). Forest classification was adopted from DowsettLemaire (1988) and Chapman (1962). The mountain's southern aspect originally supported a lush cover of semideciduous lowland forest extending from the base of the mountain at $600 \mathrm{~m}$ to roughly $950 \mathrm{~m}$. In contrast, the dominant habitat type in the surrounding plains is miombo woodland interspersed with gallery forests. The historical extent of lowland forest is unknown, but is believed to have bridged the gap between Mount Mulanje and Mount Mchese (south-east of Mount Mulanje in Figure 1), which would have encompassed sample sites $1(630 \mathrm{~m})$ and $2(720 \mathrm{~m})$ (Chapman 1962, Dowsett-
Lemair 1988). Mid-altitude forest (900-1500 m) makes up a largely continuous block within the Ruo Gorge, encompassing sample sites $3(900 \mathrm{~m}), 4(1030 \mathrm{~m}), 5$ $(1220 \mathrm{~m})$ and $6(1330 \mathrm{~m})$. Higher-altitude forest is divided into submontane (ranging from 1500-1850 m) and montane forest (up to $2100 \mathrm{~m}$ ). Much of the forest above $1600 \mathrm{~m}$ is dominated by the Mulanje cedar. Site 7 (1850 $\mathrm{m})$ was situated in the transition between submontane and montane forest, and site $8(2010 \mathrm{~m})$ was located on the plateau in a habitat composed of montane forestgrassland mosaic.

\section{METHODS}

\section{Bat sampling}

Sampling took place between September and December of 2007, and again in November and December of 2008. This period largely marks the transition between the dry and wet season. Each site along the altitudinal gradient was visited before and after the first rains for variable numbers of sampling nights depending on the cumulative capture success. We aimed to obtain similar numbers of individuals for site comparisons (i.e. equalizing sampling success, rather than effort), therefore the number of sample nights varied per site (Table 1). Multiple sampling techniques were employed at each site. At each site we used between four and six ground nets and one canopy net (Vohwinkel, Germany: size $6 \times 3 \mathrm{~m}$ and $9 \times 3 \mathrm{~m}$, respectively; five-shelved nylon nets, 16-mm mesh, 70 denier/2-ply netting). The canopy net consisted of two to four vertically stacked nets raised to a height of $c$. $12 \mathrm{~m}$ above ground at the top shelf. Additionally, we employed two four-bank, custom-built harp traps $(1.5 \times$ 1.5-m sampling area; M. Obrist, WSL, Switzerland and D. Pio, University of Lausanne, Switzerland). Nets and traps were placed opportunistically across fly-ways such as paths, rivers and habitat edges (Kunz et al. 2009), and opened from sunset until midnight or later depending on activity levels and weather. Average opening time for ground nets was $4.3 \mathrm{~h}$. At least one harp trap was left

Table 1. Sampling effort and locality information across sampling sites. One net/trap h equals the equivalent of one 6-m net/trap open for $1 \mathrm{~h}$; obs. = observations. Data from site $7(1850 \mathrm{~m})$ were excluded from most analyses.

\begin{tabular}{|c|c|c|c|c|c|c|c|c|}
\hline$\overline{\text { Site }}$ & 1 & 2 & 3 & 4 & 5 & 6 & 7 & 8 \\
\hline Altitude (m) & 630 & 720 & 900 & 1030 & 1220 & 1320 & 1850 & 2010 \\
\hline Latitude (dec. deg.) & -16.0992 & -16.0278 & -15.9715 & -15.9616 & -15.9488 & -15.9429 & -15.9351 & -15.9248 \\
\hline Longitude (dec. deg.) & 35.6245 & 35.5221 & 35.6548 & 35.6544 & 35.6515 & 35.6468 & 35.6440 & 35.6385 \\
\hline Ground effort (net h) & 50.8 & 74.6 & 43.3 & 67.4 & 56.9 & 57.9 & 49.3 & 115.5 \\
\hline Canopy effort (net h) & 27.8 & 8.3 & 64.1 & 50.3 & 51.0 & 53.6 & - & 19.5 \\
\hline Harp trap effort (trap h) & 90.5 & 72.5 & 69.0 & 53.3 & 87.0 & 150.0 & 44.8 & 203.8 \\
\hline Samples (No. nights) & 6 & 6 & 5 & 5 & 6 & 8 & 4 & 11 \\
\hline Vegetation samples (No. obs.) & 59 & 24 & 58 & 47 & 36 & 24 & 58 & 42 \\
\hline Canopy samples (No. obs.) & 30 & 15 & 30 & 24 & 18 & 14 & 28 & 21 \\
\hline
\end{tabular}


open until sunrise on almost all sampling nights (weather permitting). Canopy nets were used on only 28 of the 51 nights of sampling, and this included at least one night of sampling at every site except site 7 (1850 m, Table 1). For this reason (and because of low capture success) the site was removed from the analysis.

Standard external measurements (forearm and body mass) were taken for all captured bats, with additional measurements (tail length, head length, ear length, tragus length, horseshoe width, hind foot length and tibia length) taken from a representative sample of individuals of each species. Captures were also checked for sex and reproductive status. Field identification was based on Hayman \& Hill (1971) and Bergmans (1997). Between two and seven voucher specimens were taken from all species except Eidolon helvum (Kerr 1792), Miniopterus sp. 1 (cf. minor Peters 1867) and Rhinolophus hildebrandtii Peters 1878. Voucher specimens were preserved in $70 \%$ ethanol and deposited in the Museum of Natural History, Geneva (MHNG), the National Museums of Malawi (MoM) and the Transvaal Museum Pretoria. Field IDs were confirmed by comparing external and cranial measurements as well as qualitative characters of the voucher specimens with those of reference specimens in MHNG, The Natural History Museum, London, Senckenberg Museum Frankfurt and reference collection of JF at the University of Braunschweig. Reference echolocation calls and molecular analysis of tissue samples and wing punches from subsequently released individuals provided additional support for some species (B. Appleton, unpubl. data for Miniopterus spp. using mitochondrial genes ND2 and cytochrome $b$ ). Because the taxonomy of African Miniopterus requires further revision (Miller-Butterworth et al. 2005), the species recorded in this study are referred to as sp. 1-4, with likely affiliations to known species given in parentheses. Taxonomy follows Simmons (2005) unless otherwise stated.

\section{Analysis of species diversity}

Species richness estimators were employed at each site following the selection framework of Brose \& Martinez (2004). First, a range of species estimation values $\left(\mathrm{S}_{\text {est }}\right)$ was calculated by using a number of abundanceand incidence-based estimators (those included in EstimateS, with the addition of abundance-based variants of Jack-knife 1, 2 and 3). This range was then compared with observed species richness $\left(\mathrm{S}_{\mathrm{obs}}\right)$ to estimate sample completeness. Sample completeness at each site determines the optimal estimator to use (Brose \& Martinez 2004). The sample unit was a single night of sampling (pooling data from harp traps, ground and canopy nets) and sample size (n) ranged from four to 11. One hundred randomizations of sampling order (without replacement) were carried out for each site to derive confidence intervals. The programs SPADE version 3.1 (Species Prediction and Diversity Estimation, available at http://chao.stat.nthu.edu.tw) and EstimateS (EstimateS program and user's guide available at http:// purl.oclc.org/estimateshttp://purl.oclc.org/estimates) were used to calculate species richness with different estimators.

Fisher's $\alpha$ values for each site were calculated using the computer program Species Diversity and Richness (PISCES Conservation Ltd., Lymington, UK). All sites were tested for deviation from the log-series distribution (no significant deviations, $\mathrm{P}>0.05)$. The bias-corrected form of Shannon's entropy (Chao \& Shen 2003) was also calculated for all sites and transformed into the effective number of species $\left(\mathrm{e}^{\mathrm{H}}\right)$, also termed diversity of order one (Jost 2006), using the software SPADE. Because $\mathrm{e}^{\mathrm{H}}$ and Fisher's $\alpha$ showed similar results, only Fisher's $\alpha$ was analysed further. Statistical tests were carried out using the software R version 2.7.1 (http://www.r-project.org) and Spatial Analysis in Macroecology (SAM) version 4 (Rangel et al. 2010).

Data biases and artefacts caused by sample incompleteness are a major concern in ecological field studies (Gotelli \& Colwell 2001). We investigated undersampling bias in our dataset by inspecting smoothed species accumulation curves (SACs) and tested for relationships between diversity measures (observed and estimated species richness, Fisher's $\alpha$ ) and proxies of sampling intensity (number of nights, abundance of individuals, number of ground and canopy net hours, number of trap hours and total sampling hours). We analysed estimator precision by plotting estimated species richness against the number of samples (Walther \& Moore 2005). Stable estimator values when adding the last two samples were assumed to indicate adequate precision.

We also analysed patterns in assemblage turnover (ß-diversity) using the Chord-Normalized Expected Species Shared index (CNESS; Trueblood et al. 1994), calculated using the program COMPAH96 (Combinatorial Polythetic Agglomerative Hierarchical Clustering, available at http://alpha.es.umb.edu/ faculty/edg/files/edgwebp.htm). We produced a distance matrix that was subject to non-metric multidimensional scaling (NMDS) using the program PRIMER (Vers. 5, Plymouth, UK).

Measurements of vegetation density and canopy cover for a single sample site were respectively pooled and the frequency of each class was expressed as a percentage of all measurement points. These data were then standardized (value minus gradient mean and divided by gradient standard deviation) and entered into a principal component analysis (PCA), producing a (Euclidian) distance matrix of habitat dissimilarity between sites. We assessed whether variation in species turnover was 
correlated with habitat dissimilarity through a partial Mantel test (using the vegan package in R). The Partial Mantel test controls for a third variable, in this case geographic distance between sites (Legendre et al. 2005).

\section{Explanatory environmental variables}

At each sample site, indices of vegetation density and canopy cover were subjectively estimated by the same observer using criteria described below. Horizontal vegetation density was assessed around each netting and trapping position (on both sides of the net/trap, and on both sides of the fly way $c .10 \mathrm{~m}$ ahead and behind the net/trap, giving six measurement points per net/trap position). Values were discrete and ranged between 1 and 3 ( $1=$ uncluttered and background clutter, $2=$ intermediate clutter, $3=$ dense clutter). The classification scheme deviates slightly from that of Schnitzler \& Kalko (2001) because totally uncluttered habitat was rare in our transects. In this study, uncluttered and background clutter was considered to be open ground or very sparsely vegetated areas, with distance between neighbouring trees at breast height, or distance to edge habitat, generally greater than $5 \mathrm{~m}$. Intermediate clutter was characterized by distances between neighbouring trees at breast height, or proximity to edge, generally between 2 and $5 \mathrm{~m}$ with sparse understorey vegetation. Cluttered habitat was characterized by distances between neighbouring trees at breast height less than $2 \mathrm{~m}$ and dense understorey vegetation. Canopy cover was assessed on a six-point scale in $20 \%$-cover steps $(0=$ open to $5=$ $80-100 \%$ ) based on the field of view directly above a net position and two points $10 \mathrm{~m}$ in front and behind the net, giving a total of three measurements points per net position (see Table 1 for number of observations per site).

We used the mean score of the two measures at each site to quantify changes in vegetation density and canopy cover along the gradient. We used the standard deviation of the two measures at each site to quantify changes in vegetation heterogeneity and canopy heterogeneity along the gradient. Site values for each of these four measures were then standardized by expressing them as a negative or positive standard deviation from the gradient mean. We also summed the standardized values at each site (i.e. vegetation density + canopy cover and vegetation heterogeneity + canopy heterogeneity) to obtain combined estimates of overall habitat structure and heterogeneity, respectively. Each of these measures was then tested for a univariate correlation with bat diversity using linear regression. We also assessed whether the variation in species turnover was correlated with habitat dissimilarity between sites through a partial Mantel test (vegan package in $\mathrm{R}$ ), using geographic distance between sites as an additional variable (Appendix 1).
In addition to measures of habitat structure, we developed a series of environmental variables representing several factors known to play a role in altitude-diversity relationships. These were average nightly temperature and relative humidity at the time of sampling, mean annual temperature, mean annual relative humidity, total and forested area within 100$\mathrm{m}$ altitudinal bands centred around each sampling site, and the Normalized Difference Vegetation Index (NDVI) as a proxy for productivity. Because the low number of sampling sites prevented application of a multivariate approach to elucidate the role of these predictors, such as stepwise multiple regression (Sanders et al. 2007), we tested each predictor for a univariate correlation with diversity using simple linear regression. Additional information pertaining to the study, including a detailed account of the methodology used to derive these additional variables, can be found at http://sites.google.com/site/jakobfahr.

\section{RESULTS}

\section{Sampling summary}

A total of 51 sampling nights across eight sites yielded 723 individuals, which comprised 30 species, 19 genera and seven families (Tables 1 and 2). We captured additional individuals, and one extra species, Myotis welwitschii (Gray 1866), during opportunistic sampling at various localities. Sampling effort differed markedly across sites (Table 1), as did the number of captured individuals and overall capture success (Table 2). Overall capture success, measured as the number of individuals captured per ground net, canopy net and trap $\mathrm{h}$, also differed across sites. Fruit bat captures were biased towards canopy nets with a ratio of canopy to ground net capture success of 1.1-8.8, with the highest values at sites 3 (ratio $=$ 8.8 ) and 4 (ratio = 5.7). In animalivorous bats, the trend was reversed with capture success always heavily biased towards ground nets (C:G ratio of 0.03-0.228).

A smoothed species accumulation curve for our entire dataset (i.e. all sites pooled, including additional sites not included in the analysis) appeared to level off, indicating that a large proportion of the regional species pool had been sampled (Figure 2a). Observed SACs at the site level showed varying degrees of completeness. Three sites $(630 \mathrm{~m}, 1320 \mathrm{~m}$ and $2010 \mathrm{~m})$ were clearly in a stage of accumulation, a further two sites $(900 \mathrm{~m}$ and 1220 m) approached an inflection point, and only two sites $(720 \mathrm{~m}$ and $1030 \mathrm{~m}$ ) showed signs of levelling off (Figure $2 b)$. Precision of estimators was satisfactory at almost all sites, with only one site $(1220 \mathrm{~m})$ showing signs of imprecision (data not shown). $S_{\text {obs }}$ was significantly and positively correlated to the number of individuals $(n=7$, 
Table 2. Individuals per species and site along the altitudinal gradient, including total captures. ${ }^{*}=$ specific status assigned based on very small forearm length and echolocation calls distinct from other Miniopterus species. One additional species, Myotis welwitschii, was captured during opportunistic sampling and is not included in this table.

\begin{tabular}{|c|c|c|c|c|c|c|c|c|c|}
\hline \multirow{3}{*}{$\begin{array}{l}\text { Site: } \\
\text { Alt. (m): }\end{array}$} & \multicolumn{8}{|c|}{ Number of individuals per site } & \multirow[b]{3}{*}{ Total } \\
\hline & 1 & 2 & 3 & 4 & 5 & 6 & 7 & 8 & \\
\hline & 630 & 720 & 900 & 1030 & 1220 & 1320 & 1850 & 2010 & \\
\hline \multicolumn{10}{|l|}{ Pteropodidae } \\
\hline Epomophorus crypturus Peters 1852 & 7 & 0 & 0 & 0 & 0 & 0 & 0 & 0 & 7 \\
\hline Epomophorus wahlbergi (Sundevall 1846) & 0 & 12 & 6 & 10 & 5 & 1 & 0 & 0 & 34 \\
\hline Lissonycteris angolensis (Bocage 1898) & 0 & 5 & 1 & 1 & 2 & 3 & 0 & 0 & 12 \\
\hline Myonycteris relicta Bergmans 1980 & 0 & 0 & 0 & 1 & 0 & 0 & 0 & 0 & 1 \\
\hline Rousettus aegyptiacus (E. Geoffroy 1810) & 5 & 47 & 7 & 19 & 2 & 0 & 0 & 0 & 80 \\
\hline Eidolon helvum (Kerr 1792) & 0 & 0 & 0 & 0 & 1 & 1 & 0 & 0 & 2 \\
\hline \multicolumn{10}{|l|}{ Rhinolophidae } \\
\hline Rhinolophus blasii Peters 1866 & 7 & 10 & 47 & 198 & 70 & 13 & 0 & 0 & 345 \\
\hline Rhinolophus clivosus Cretzschmar 1828 & 1 & 8 & 17 & 14 & 3 & 3 & 9 & 7 & 62 \\
\hline Rhinolophus fumigatus Rüppell 1842 & 0 & 4 & 0 & 0 & 0 & 0 & 0 & 0 & 4 \\
\hline Rhinolophus hildebrandtii Peters 1878 & 0 & 1 & 0 & 1 & 0 & 0 & 0 & 0 & 2 \\
\hline Rhinolophus simulator Andersen 1904 & 20 & 4 & 0 & 6 & 0 & 0 & 0 & 0 & 30 \\
\hline \multicolumn{10}{|l|}{ Hipposideridae } \\
\hline Hipposideros ruber (Noack 1893) & 0 & 2 & 1 & 0 & 0 & 0 & 0 & 0 & 3 \\
\hline \multicolumn{10}{|l|}{ Nycteridae } \\
\hline Nycteris hispida (Schreber 1774) & 0 & 2 & 0 & 0 & 0 & 0 & 0 & 0 & 2 \\
\hline Nycteris thebaica E. Geoffroy 1818 & 0 & 1 & 2 & 0 & 1 & 0 & 0 & 0 & 4 \\
\hline \multicolumn{10}{|l|}{ Vespertilionidae } \\
\hline Myotis tricolor (Temminck 1832) & 2 & 2 & 1 & 3 & 1 & 6 & 0 & 12 & 27 \\
\hline Kerivoula argentata Tomes 1861 & 0 & 1 & 0 & 0 & 0 & 0 & 0 & 0 & 1 \\
\hline Kerivoula lanosa (A. Smith 1847) & 0 & 0 & 0 & 2 & 1 & 2 & 0 & 0 & 5 \\
\hline Eptesicus hottentotus (A. Smith 1833) & 0 & 0 & 0 & 0 & 0 & 0 & 0 & 2 & 2 \\
\hline Laephotis botswanae Setzer 1971 & 7 & 8 & 2 & 0 & 0 & 0 & 0 & 0 & 17 \\
\hline Mimetillus moloneyi (Thomas 1891) & 1 & 0 & 0 & 0 & 0 & 0 & 0 & 0 & 1 \\
\hline Neoromicia nana (Peters 1852) & 1 & 11 & 0 & 2 & 0 & 0 & 0 & 0 & 14 \\
\hline Pipistrellus grandidieri (Dobson 1876) & 2 & 0 & 0 & 0 & 0 & 0 & 0 & 0 & 2 \\
\hline Pipistrellus hesperidus (Temminck 1840) & 1 & 10 & 0 & 3 & 3 & 0 & 1 & 0 & 18 \\
\hline Scotophilus dinganii (A. Smith 1833) & 0 & 1 & 0 & 0 & 0 & 0 & 0 & 0 & 1 \\
\hline \multicolumn{10}{|l|}{ Miniopteridae } \\
\hline Miniopterus sp. 1 (minor Peters 1867) * & 0 & 3 & 0 & 0 & 0 & 0 & 0 & 0 & 3 \\
\hline Miniopterus sp. 2 (fraterculus Thomas \& Schwann 1906) & 2 & 8 & 0 & 3 & 3 & 2 & 0 & 1 & 19 \\
\hline Miniopterus sp. 3 (natalensis (A. Smith 1834)) & 0 & 0 & 0 & 1 & 1 & 0 & 0 & 0 & 2 \\
\hline Miniopterus sp. 4 (inflatus Thomas 1903) & 0 & 0 & 0 & 3 & 16 & 0 & 0 & 1 & 20 \\
\hline \multicolumn{10}{|l|}{ Molossidae } \\
\hline Tadarida aegyptiaca (E. Geoffroy 1818) & 0 & 0 & 1 & 0 & 1 & 0 & 0 & 0 & 2 \\
\hline Mops cf. brachypterus (Peters 1852) & 0 & 0 & 0 & 1 & 0 & 0 & 0 & 0 & 1 \\
\hline Total & 56 & 140 & 85 & 268 & 110 & 31 & 10 & 23 & 723 \\
\hline Observed species richness & 12 & 19 & 10 & 16 & 14 & 8 & 2 & 5 & 30 \\
\hline Ground net capture success (ind. per net h) & 0.45 & 1.58 & 0.62 & 1.07 & 0.74 & 0.12 & 0.20 & 0.19 & 0.59 \\
\hline Canopy net capture success (ind. per net h) & 0.25 & 1.08 & 0.23 & 0.54 & 0.12 & 0.11 & n.a. & 0.05 & 0.26 \\
\hline Harp trap capture success (ind. per trap h) & 1.46 & 1.91 & 1.45 & 1.35 & 1.42 & 1.35 & 0.00 & 1.91 & 0.48 \\
\hline
\end{tabular}

$\left.\mathrm{r}^{2}=0.81, \mathrm{P}<0.01\right)$. Employing species richness estimators weakened this correlation, but the relationship remained significant $\left(\mathrm{n}=7, \mathrm{r}^{2}=0.74, \mathrm{P}<0.05\right)$. Fisher's $\alpha$ was not significantly correlated to any measures of sampling effort. Appendix 1 contains a summary of all regression parameters.

\section{Species diversity along the gradient}

Estimated species richness $\left(S_{\text {est }}\right)$ followed a low-plateau pattern with richness remaining comparably high until the mid-altitudes (peaking at c. $1220 \mathrm{~m}$ ), before decreasing thereafter (Figure 3). In order to investigate if the pattern was driven by the diversity of fruit bats in the mid-altitudes (where the highest species richness of Pteropodidae occurred), a second analysis was performed including only animalivorous species. Although less pronounced, the shape of the pattern remained the same, but the peak shifted to $720 \mathrm{~m}$ (data not shown). Fisher's $\alpha$ declined with altitude (data not shown), and this relationship was significant even when accounting for spatial non-independence of samples (Dutilleul's method, software SAM v 4: $\mathrm{n}=7, \mathrm{r}=-0.811, \mathrm{~F}_{\text {corr }}=8.1, \mathrm{df}_{\text {corr }}=$ $4.2, \mathrm{P}=0.044)$. 


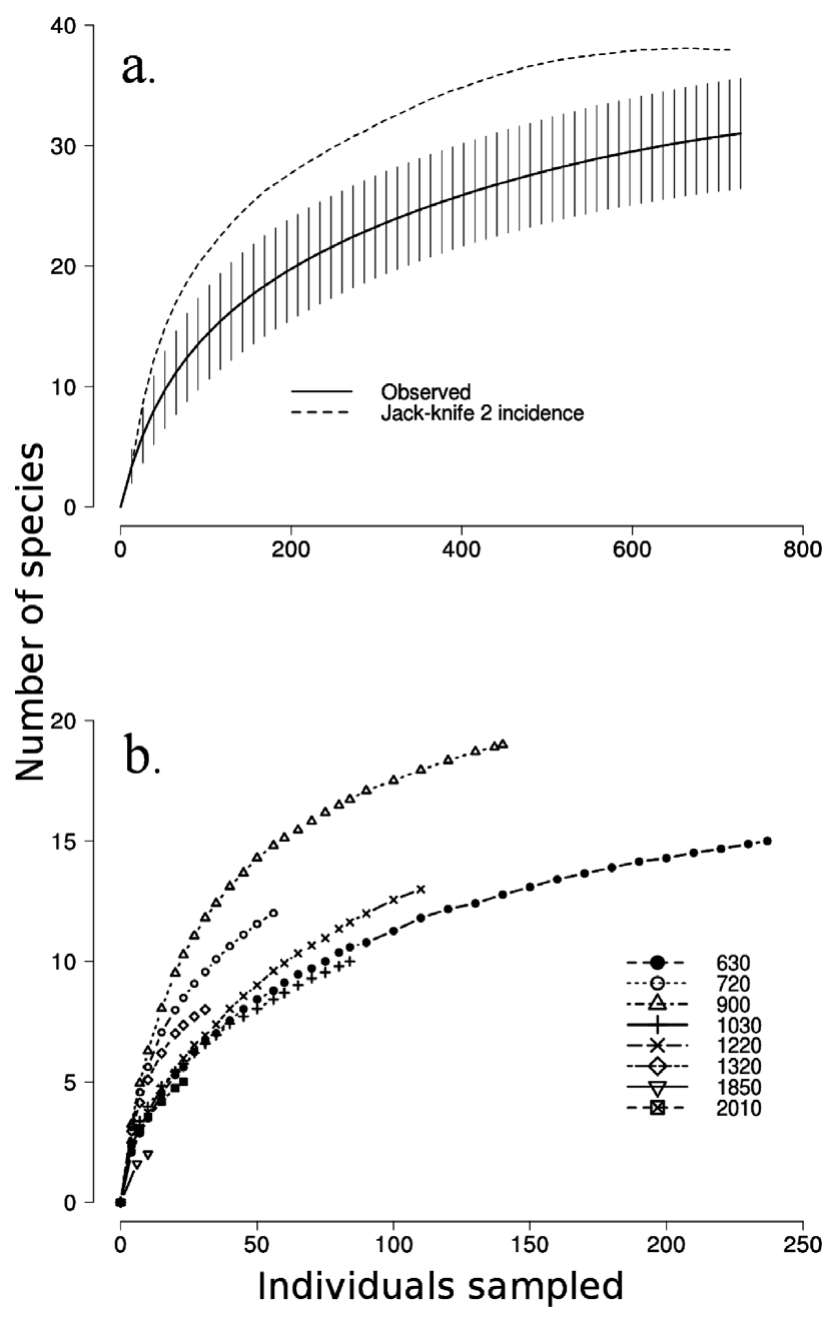

Figure 2 Smoothed species accumulation curves (SACs) for pooled data from all sampling sites (a), which includes additional opportunistic captures from sites not included in the analysis, and separately for all sampling sites (b). Vertical lines around observed species richness curve (a) represent upper and lower 95\% confidence intervals, dotted line represents estimated species richness (Jack-knife 2).

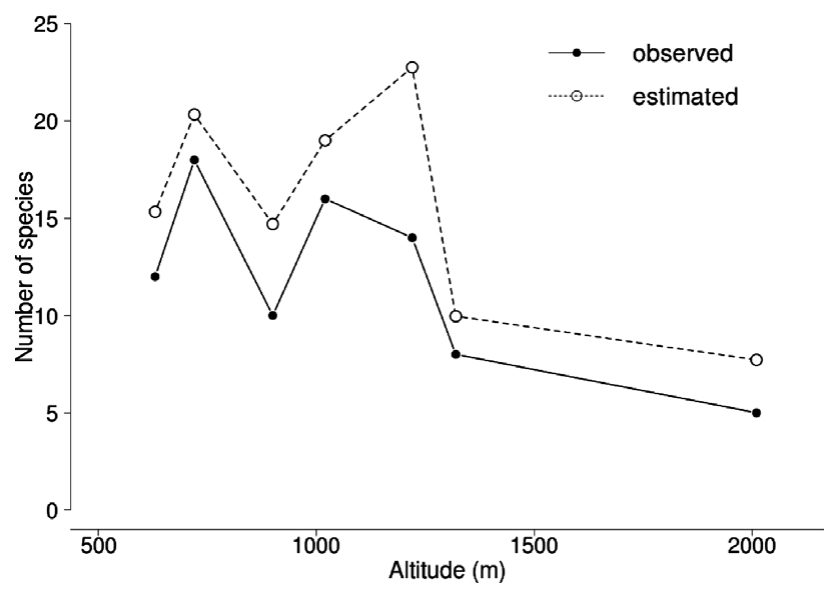

Figure 3 Changes in observed (solid line, filled circles) and estimated species richness (dotted line, open circles) with altitude.
Non-metric multidimensional scaling (NMDS) of the CNESS dissimilarity matrix resulted in a two-dimensional ordination plot (two-dimensional stress value 0.003; data not shown). When the order of sites is considered, separation along the $\mathrm{x}$-axis mirrored changes in altitude. Habitat dissimilarity between sites was significantly correlated to variation in assemblage dissimilarity, even after correcting for geographic distance (partial Mantel test; $\mathrm{R}=0.71, \mathrm{P}<0.01$ ).

\section{Environmental correlates of local diversity}

$S_{\text {est }}$ was significantly correlated with vegetation density $\left(\mathrm{n}=7, \mathrm{r}^{2}=0.75, \mathrm{P}<0.05\right)$, canopy cover $\left(\mathrm{n}=7, \mathrm{r}^{2}=\right.$ $0.65, \mathrm{P}<0.05)$ and combined habitat structure $(\mathrm{n}=$ $\left.7, \mathrm{r}^{2}=0.84, \mathrm{P}<0.01\right)$. $\mathrm{S}_{\text {est }}$ was further negatively correlated with combined habitat heterogeneity $(\mathrm{n}=$ $\left.7, \mathrm{r}^{2}=0.73, \mathrm{P}<0.05\right)$, but not to vegetation heterogeneity or canopy heterogeneity alone (Appendix 1 ). We did not detect any strong or significant correlations between $S_{\text {est }}$ and the additional environmental variables $\left(\mathrm{r}^{2}\right.$ values ranging 0.04-0.47, the latter with mean annual relative humidity). Fisher's $\alpha$ was strongly, but negatively, correlated to vegetation heterogeneity $(\mathrm{n}=7$, $\left.\mathrm{r}^{2}=0.77, \mathrm{P}<0.01\right)$ and combined habitat heterogeneity $\left(\mathrm{n}=7, \mathrm{r}^{2}=0.92, \mathrm{P}<0.001\right)$. It was also correlated to mean annual relative humidity $\left(n=7, r^{2}=0.66\right.$, $\mathrm{P}<0.05)$. Although we did not account for covariances among predictors using a multivariate approach, we did assess the degree of covariance between predictors by regressing them against altitude. In particular, altitude was negatively and significantly correlated to mean annual temperature $\left(\mathrm{n}=7, \mathrm{r}^{2}=0.87, \mathrm{P}<0.001\right)$, mean annual relative humidity $\left(\mathrm{n}=7, \mathrm{r}^{2}=0.95, \mathrm{P}<0.001\right)$, NDVI $\left(\mathrm{n}=7, \mathrm{r}^{2}=0.63, \mathrm{P}<0.05\right)$ and canopy cover $\left(\mathrm{n}=7, \mathrm{r}^{2}=0.61, \mathrm{P}<0.05\right)$.

\section{Climate model of McCain}

We tested whether our findings fit the climate model proposed by McCain (2007b), which postulated that the species richness peak of bats along altitudinal gradients is a function of regional climate approximated by latitude. According to the geographic position of Mount Mulanje $\left(15.96^{\circ} \mathrm{S}\right)$, the climate model predicts a peak at $c .1000$ $\mathrm{m}$ asl. Our analysis revealed a peak at $1220 \mathrm{~m}$ for estimated species richness (Figure 3), which preserved the significance and explanatory power of McCain's climate model, when re-analysed with our data included $(n=13$, $\left.\mathrm{r}^{2}=0.44, \mathrm{P}=0.012\right)$. When only animalivorous species were analysed, the peak in richness in our study shifted to $720 \mathrm{~m}$. Again, this supports the climate model, which predicts a richness peak for animalivorous bats at $c .700$ m (McCain 2007b, Figure 3c). Likewise, combining our 
results with the global dataset did not affect the model $(\mathrm{n}=$ $\left.12, \mathrm{r}^{2}=0.58, \mathrm{P}=0.003\right)$. However, the shift in the peak in richness for animalivorous bats compared with all bat species relied on negligible changes in estimated species richness (14.9 species at $720 \mathrm{~m}$ against 14.5 species at $1220 \mathrm{~m})$.

\section{DISCUSSION}

\section{Implications for the altitude-diversity relationship}

The paucity of sampling sites in our study prevented a multivariate treatment of our explanatory data (predictors) therefore we conducted a series of linear regressions with predictors and diversity measures. Because each variable was standardized before analysis, regression parameters could be directly compared across predictors. Yet because of the considerable collinearity across predictors (e.g. altitude was significantly correlated to temperature, humidity, NDVI and canopy cover), inferences are highly limited. In general, predictors related to habitat structure measured in the field (e.g. vegetation density, canopy cover, habitat heterogeneity) had high model-fit values (i.e. $\mathrm{r}^{2}$ values ranging $0.65-0.84$ ). In contrast, model-fit statistics for the additional climatic and geometric variables were comparatively low $\left(r^{2}=0.04-\right.$ 0.47), the strongest of which was a negative relationship with mean annual relative humidity.

In terms of rigorously testing the various hypotheses proposed to explain altitude-diversity relationships, our data are largely inadequate, but some general conclusions arise. It is likely that the small sampling grain of our study shifted importance from overarching climatic and geometric influences to small-scale variation in biotic factors embodied in our proxies of habitat structure. Spatial grain is known to affect the form and mechanisms underlying many diversity gradients (Rahbek 2005), particularly area, which is more influential at larger sampling grains (Romdal \& Grytnes 2007, Sanders 2002). This may explain the lack of a strong effect in our data. We did not investigate the mid-domain effect (MDE) because we deemed our sampling data insufficient to reconstruct species' altitudinal ranges, and because of the lack of theoretical support for the MDE concept (Hawkins et al. 2005). Of the climatic variables, annual relative humidity showed the strongest relationship with estimated species richness, and the relationship with Fisher's $\alpha$ was significant. According to the climate model of McCain (2007b), richness is expected to peak on mountains with a dry base where a unimodal water availability gradient intersects with a declining temperature gradient. In our study, both temperature and humidity declined with altitude, indicating that we did not sample low enough (or outside of the mountain's rain shadow) to detect significant limits to water availability. This is likely due to the fact that Mount Mulanje itself rises from an undulating plateau at 500-600 m, with further declines in altitude occurring over much larger distances than contained within our gradient.

Predictors related to habitat structure were strongly correlated with our richness data, indicating some form of biotic mechanism influencing the altitudediversity relationship (Graham 1990, Sánchez-Cordero 2001, Terborgh 1977). Our simple measure of habitat heterogeneity was negatively correlated to both estimated species richness and Fisher's $\alpha$. Since the latter exhibited a stronger (and highly significant) relationship, it indicates that uniformity in understorey vegetation and a canopy cover influence both species richness and the distribution of individuals between species (i.e. evenness), thereby increasing Fisher's $\alpha$ relative to $S_{\text {est }}$. At the same time, habitat heterogeneity explained a significant degree of species compositional change between sites, potentially leading to increased gamma diversity at the landscape scale (Fahr \& Kalko 2011).

\section{Potential sources of bias}

Species accumulation curves (SACs) indicated observed species inventories were incomplete at numerous sites, yet only one metric of sampling effort, abundance of individuals, was positively and significantly correlated to $S_{\text {obs. }}$. Applying richness estimators weakened the correlation but it remained significant, indicating that either undersampling bias remained in $S_{\text {est }}$ or the relationship was driven by alternative (environmental) factors, such as productivity (Beck et al. 2011). While we did not have data available to investigate this further, we favour the latter explanation because (1) we found negative relationships with other measures of sampling effort (i.e. number of nights, trapping and total sampling hours), (2) our assessment of estimator precision was generally positive, and (3) simulation studies have shown that species richness estimators perform reliably at the level of sampling intensity of our least-surveyed site (five samples; Walther \& Moore 2005). Fisher's $\alpha$ has also been shown to perform well at low to medium sampling intensities (Beck \& Schwanghart 2010, Fisher et al. 1943, Hurlbert 1971), and showed no significant relationship with any proxy of sampling effort. Some authors (Sanders et al. 2007) have used Fisher's $\alpha$ as a direct proxy for species richness because of its robustness to undersampling, but we avoided this because the two indices measure different properties of diversity, and Fisher's $\alpha$ may be misleading where samples approach completeness (Beck \& Schwanghart 2010).

A second potential criticism of our study is that we did not assess or account for the effects of anthropogenic 
disturbance, which acted at variable intensities along the gradient, including the widespread clearance of lowland forest, small-scale degradation of low- and midaltitude forests, and man-made fires at the top of the gradient (see Bayliss et al. 2007 for an account of the anthropogenic threats facing Mount Mulanje). While anthropogenic disturbance is known to exert a strong influence on the composition and abundance of local bat assemblages (Racey \& Entwistle 2003), we did not collect data on the type of disturbance and its intensity along the gradient, and thus cannot assess its influence on our results. Finally, we lacked comprehensive seasonal representation, sampling each site at the end of the dry season and in beginning of the wet season. We acknowledge that additional data from other times in the year may potentially alter the observed pattern (Beck et al. 2010, Sánchez-Cordero 2001).

\section{Conservation relevance}

The predictive ability of the climate model (McCain $2007 \mathrm{~b}$ ) is impressive, and potentially valuable for conservation assessments of poorly surveyed mountain areas. However, further testing across a range of representative gradients is recommended, particularly within the unique geological and climatic context of the African continent, for which our study is the first. Coastal and montane forests across East and Southern Africa are known to be important centres of bat diversity and endemism (Cockle et al. 1998, Kock et al. 2000, Monadjem et al. 2010). We recorded important distributional records of forest-associated species such as Myonycteris relicta and Lissonycteris angolensis, for which isolated montane forests likely constitute important regional stepping stones of habitat.

Mount Mulanje appears to be an important centre of diversity for bats at both a national and regional scale, harbouring a significant portion of Malawi's bat diversity. Our results indicate that future conservation efforts should continue to focus on the strict protection of mid-altitude forest while aiming to increase lowland forest cover around the base of the mountain.

\section{ACKNOWLEDGEMENTS}

We express our appreciation to the National Geographic Society/Waitts Institute for Discovery (grant number W37-08), the Josef und Olga Tomcsik-Stiftung, the Freiwillige Akademische Gesellschaft Basel and the Swiss Academy of Sciences for funding. We also thank the National Research Council of Malawi and the Department of Forestry (permit numbers TC/14/2/2007/01 and $6 / 5 / 2005 / 3$, respectively), the National Museums of Malawi and the Mulanje Mountain Conservation Trust.
We are grateful to Julian Bayliss, Dorothea Pio and Blessings Walawala, Teresa Kearney and Earnest Seamark for assistance and advice. Peter Nagel supervised the research at Basel University. Manuel Ruedi and the technical staff at MHNG prepared the voucher specimens. The World Bat Library (Muséum Histoire Naturelle de Genève) provided access to some literature.

\section{LITERATURE CITED}

BAYLISS, J., MAKUNGWA, S., HECHT, J., NANGOMA, D. \& BRUESSOW, C. 2007. Saving the Island in the Sky: the plight of the Mount Mulanje cedar Widdringtonia whytei in Malawi. Oryx 41:64-69.

BECK, J., ALTERMATT, F., HAGMANN, R. \& LANG, S. 2010. Seasonality in the altitude-diversity pattern of alpine moths. Basic and Applied Ecology 11:714-722.

BECK, J. \& SCHWANGHART, W. 2010. Comparing measures of species diversity from incomplete inventories: an update. Methods in Ecology and Evolution 1:38-44.

BECK, J., BREHM, G. \& FIEDLER, K. 2011. Links between the environment, abundance and diversity of Andean moths. Biotropica 43:208-217.

BERGMANS, W. 1997. Taxonomy and biogeography of African fruit bats (Mammalia, Megachiroptera). 5. The genera Lissonycteris Andersen, 1912, Myonycteris Matschie, 1899 and Megaloglossus Pagenstecher, 1885; general remarks and conclusions; annex: key to all species. Beaufortia 47:11-90.

BOUVIER, I. 2006. Mount Mulanje land cover time series analysis. Report to the Community Partnerships for Sustainable Resource Management in Malawi (COMPASS II), Blantyre, Malawi.

BROSE, U. \& MARTINEZ, N. D. 2004. Estimating the richness of species with variable mobility. Oikos 105:292-300.

CHAO, A. \& SHEN, T. J. 2003. Nonparametric estimation of Shannon's index of diversity when there are unseen species in sample. Environmental and Ecological Statistics 10:429-443.

CHAPMAN, J.D. 1962. The vegetation of the Mlanje Mountains, Nyasaland. Government Printer Zomba, Nyasaland. 78 pp.

COCKLE, A., KOCK, D., STUBLEFIELD, L., HOWELL, K. \& BURGESS, N. 1998. Bat assemblages in Tanzanian coastal forests. Mammalia 62:53-68.

COLWELL, R. K. \& LEES, D. C. 2000. The mid-domain effect: geometric constraints on the geography of species richness. Trends in Ecology and Evolution 15:70-76.

DOWSETT-LEMAIRE, F. 1988. The forest vegetation of Mount Mulanje (Malawi): A floristic and chorological study along an altitudinal gradient (650-1950 m). Bulletin du Jardin Botanique National de Belgique 58:77-107.

FAHR, J. \& KALKO, E. K. V. 2011. Biome transitions as centres of diversity: habitat heterogeneity and diversity patterns of West African bat assemblages across spatial scales. Ecography 34:177-195.

FINDLEY, J. S. \& WILSON, D. E. 1983. Are bats rare in tropical Africa? Biotropica 15:299-303. 
FISHER, R. A., CORBET, A. S. \& WILLIAMS, C. B. 1943. The relation between the number of species and the number of indivuduals in a random sample of an animal population. Journal of Animal Ecology 12:42-58.

GOODMAN, S. M. \& RASOLONANDRASANA, B.P.N. 2001. Elevational zonation of birds, insectivores, rodents and primates on the slopes of the Andringitra Massif, Madagascar. Journal of Natural History 35:285-305.

GOTELLI, N. J. \& COLWELL, R. K. 2001. Quantifying biodiversity: procedures and pitfalls in the measurement and comparison of species richness. Ecology Letters 4:379-391.

GRAHAM, G. L. 1990. Bats versus birds: comparisons among Peruvian volant vertebrate faunas along an elevational gradient. Journal of Biogeography 17:657-668.

GRYTNES, J.-A. \& MCCAIN, C. M. 2007. Elevational trends in biodiversity. Pp. 1-8 in Levin, S. A. (ed.). Encyclopedia of biodiversity. Elsevier, New York.

HAPPOLD, D. C. D., HAPPOLD, M. \& HILL, J.E. 1987. The bats of Malawi. Mammalia 51:337-414.

HAPPOLD, M. \& HAPPOLD, D. C. D. 1997. New records of bats (Chiroptera: Mammalia) from Malawi, east-central Africa, with an assessment of their status and conservation. Journal of Natural History 31:805-836.

HAWKINS, B. A., DINIZ-FILHO, J. A. F. \& WEIS, A. E. 2005. The middomain effect and diversity gradients: is there anything to learn? American Naturalist 166:E140-E143.

HAYMAN, R. W. \& HILL, J. E. 1971. Order Chiroptera. Pp. 1-73 in Meester, J. \& Setzer, H. W. (eds.). The mammals of Africa. An identification manual. Smithsonian Institution Press, Washington, DC.

HURLBERT, S. H. 1971. The nonconcept of species diversity: a critique and alternative parameters. Ecology 52:577-586.

JOST, L. 2006. Entropy and diversity. Oikos 113:363-375.

KOCK, D., CSORBA, G. \& HOWELL, K. M. 2000. Rhinolophus maendeleo n. sp. from Tanzania, a horseshoe bat noteworthy for its systematics and biogeography. Senckenbergiana Biologica 80:233-239.

KUNZ, T.H., HODGKISON, R.\& WEISE, C.D. 2009. Methods of capturing and handling bats. Pp 3-35 in Kunz, T. H. \& Parsons, S. (eds.). Ecological and behavioral methods for the study of bats. (Second edition). John Hopkins University Press, Baltimore. 901 pp.

LEGENDRE, P., BORCARD, D. \& PERES-NETO, P. R. 2005. Analyzing beta diversity: partitioning the spatial variation of community composition data. Ecological Monographs 75:435-450.

MCCAIN, C. M. 2007a. Area and mammalian elevational diversity. Ecology 88:76-86.

MCCAIN, C. M. 2007b. Could temperature and water availability drive elevational richness patterns? A global case study for bats. Global Ecology and Biogeography 16:1-13.

MEGGERS, B. J., AYENSU, E. S. \& DUCKWORTH, W. D. (eds.). 1973. Tropical forest ecosystems in Africa and South America: a com- parative review. Smithsonian Institute Press, Washington, DC. 350 pp.

MILLER-BUTTERWORTH, C. M., EICK, G., JACOBS, D. S., SCHOEMAN, M. C. \& HARLEY, E. H. 2005. Genetic and phenotypic differences between South African long-fingered bats, with a global miniopterine phylogeny. Journal of Mammalogy 86:1121-1135.

MONADJEM, A., SCHOEMAN, M. C., RESIDE, A., PIO, D. V., STOFFBERG, S., BAYLISS, J., COTTERILL, F. P. D., CURRAN, M., KOPP, M. \& TAYLOR, P. J. 2010. A recent inventory of the bats of Mozambique with documentation of seven new species for the country. Acta Chiropterologica 12:371-391.

RACEY, P. A. \& ENTWISTLE, A. C. 2003. Conservation ecology of bats. Pp. 680-743 in Kunz, T. H. \& Fenton, M. B. (eds.). Bat ecology. University of Chicago Press, Chicago.

RAHBEK, C. 2005. The role of spatial scale and the perception of largescale species-richness patterns. Ecology Letters 8:224-239.

RANGEL, T. F., DINIZ FILHO, J. A. F. \& BINI, L. M. 2010. SAM: a comprehensive application for Spatial Analysis in Macroecology. Ecography 33:46-50.

ROMDAL, T. S. \& GRYTNES, J. A. 2007. An indirect area effect on elevational species richness patterns. Ecography 30:440-448.

SÁNCHEZ-CORDERO, V. 2001. Elevational gradients of diversity for rodents and bats in Oaxaca, Mexico. Global Ecology and Biogeography Letters 10:63-76.

SANDERS, N. J. 2002. Elevational gradients in ant species richness: area, geometry, and Rapoport's rule. Ecography 25:25-32.

SANDERS, N. J., LESSARD, J., FITZPATRICK, M. C. \& DUNN, R. R. 2007. Temperature, but not productivity or geometry, predicts elevational diversity gradients in ants across spatial grains. Global Ecology and Biogeography 16:640-649.

SCHNITZLER, H. U. \& KALKO, E. V. 2001. Echolocation by insect-eating bats. BioScience 51:557-569.

SIMMONS, N. B. 2005. Order Chiroptera. Pp. 312-529 in Wilson, D. E. \& Reeder, D. M. (eds.). Mammal species of the world: a taxonomic and geographic reference. Vol. 1 (Third edition). John Hopkins University Press, Baltimore. 743 pp.

SMITH, S. A., NIETO MONTES DE OCA, A., REEDER, T. W. \& WIENS, J. J. 2007. A phylogenetic perspective on elevational species richness patterns in middle American treefrogs: why so few species in lowland tropical rainforests? Evolution 61:1188-1207.

TERBORGH, J. 1977. Bird species diversity on an Andean elevational gradient. Ecology 58:1007-1019.

TRUEBLOOD, D. D., GALLAGHER, E. D. \& GOULD, D. M. 1994. Three stages of seasonal succession on the Savin Hill Cove mudflat, Boston Harbor. Limnology and Oceanography 39:1440-1454.

WALTHER, B. A. \& MOORE, J. L. 2005. The concepts of bias, precision and accuracy, and their use in testing the performance of species richness estimators, with a literature review of estimator performance. Ecography 28:815-829. 
Appendix 1. Simple linear regression applied to a range of variables relating to sample completeness and environment, with most data log-transformed to conform to a normal distribution (except temperature which was already normally distributed). Observed and estimated species richness was also log-transformed for regressions with area variables. Environmental variables were further normalized by subtracting the gradient mean and dividing by the standard deviation (SD). Data on mean annual temperature and relative humidity were created by interpolating weather station data using the commercial software MeteoNorm (http://www.meteonorm.com). Altitudinal area band figures were calculated using a GIS (Geographic Resource Analysis Support System, ver. 6.4.1; grass.fbk.eu/) and the SRTM 90 m resolution digital elevation model (www2.jpl.nasa.gov/srtm/). Forest area was approximated using categories 40 through 100 of the ESA Globecover 2009 landcover dataset (www.esa.int). A Normalized Difference Vegetation Index was computed using bands 3 and 4 from an orthorectified Landsat ETM+ image (available at www.landsat.org), acquired on 9 July 2002. Further information is available at http://sites.google.com/site/jakobfahr. ${ }^{*}=\mathrm{P}<0.05,{ }^{* *}=\mathrm{P}<0.01,{ }^{* * *}=\mathrm{P}<0.001$.

\begin{tabular}{|c|c|c|c|c|c|c|}
\hline \multirow[b]{2}{*}{ Variable (log-transformed and normalized) } & \multicolumn{2}{|c|}{$\mathrm{S}_{\mathrm{obs}}$} & \multicolumn{2}{|c|}{$S_{\text {est }}$} & \multicolumn{2}{|c|}{ Fisher's $\alpha$} \\
\hline & Coeff. & R-squared & Coeff. & R-squared & Coeff. & R-squared \\
\hline log(Number of nights) & $-3.36^{*}$ & $0.54^{*}$ & $-4.08^{*}$ & $0.56^{*}$ & -0.63 & 0.24 \\
\hline $\log ($ Abundance of individuals $)$ & $4.10^{* *}$ & $0.81^{* *}$ & $4.71^{*}$ & $0.74^{*}$ & 0.68 & 0.28 \\
\hline Ground net hours & -0.07 & 0.12 & -0.10 & 0.19 & -0.02 & 0.14 \\
\hline Canopy net hours & 0.03 & 0.02 & 0.01 & 0.00 & -0.02 & 0.15 \\
\hline Trapping hours & $-0.07^{*}$ & $0.71^{*}$ & $-0.08^{*}$ & $0.68^{*}$ & -0.01 & 0.37 \\
\hline $\log$ (Sum sampling hours) & $-13.9^{*}$ & $0.75^{*}$ & $-15.4^{*}$ & $0.64^{*}$ & $-3.39^{*}$ & $0.57^{*}$ \\
\hline $\log$ (Mean nightly temperature) & 2.68 & 0.35 & 2.67 & 0.24 & 0.96 & 0.57 \\
\hline $\log ($ Mean nightly relative humidity) & -1.37 & 0.09 & -2.70 & 0.24 & -0.46 & 0.13 \\
\hline Mean annual temperature & 2.73 & 0.36 & 2.60 & 0.23 & 0.91 & 0.51 \\
\hline $\log ($ Mean annual relative humidity) & 3.38 & 0.55 & 3.74 & 0.47 & $1.03^{*}$ & $0.66^{*}$ \\
\hline $\log$ (Area within 100-m altitudinal bands) & 0.18 & 0.17 & 0.12 & 0.09 & 0.86 & 0.46 \\
\hline $\log$ (Forest area within 100-m altitudinal bands) & 0.20 & 0.21 & 0.13 & 0.11 & 0.94 & 0.55 \\
\hline $\log (\mathrm{NDVI}$ index $)$ & 1.73 & 0.14 & 1.04 & 0.04 & 0.73 & 0.33 \\
\hline Vegetation density & 3.27 & 0.51 & $4.74^{*}$ & $0.75^{*}$ & 0.69 & 0.29 \\
\hline Canopy cover & $3.53^{*}$ & $0.60^{*}$ & $4.42 *$ & $0.65^{*}$ & 0.71 & 0.31 \\
\hline Habitat structure (veg + can) & $2.03^{*}$ & $0.66^{*}$ & $2.74^{* *}$ & $0.84^{* *}$ & 0.42 & 0.36 \\
\hline Vegetation heterogeneity (SD) & -2.98 & 0.43 & -3.31 & 0.37 & $-1.11^{* *}$ & $0.77^{* *}$ \\
\hline Canopy heterogeneity (SD) & $-3.55^{*}$ & $0.61^{*}$ & -4.02 & 0.54 & -0.79 & 0.39 \\
\hline
\end{tabular}

